\title{
Using 0*NET to Develop a Framework of Job Characteristics to Potentially Improve the Predictive Validity of Personality Measures
}

Jeremy Burrus

Professional Examination Service

Jason D. Way

ACT, Inc.

Follow this and additional works at: https://scholarworks.bgsu.edu/pad

Part of the Human Resources Management Commons, Industrial and Organizational Psychology Commons, and the Other Psychology Commons

How does access to this work benefit you? Let us know!

\section{Recommended Citation}

Burrus, Jeremy and Way, Jason D. (2017) "Using O*NET to Develop a Framework of Job Characteristics to Potentially Improve the Predictive Validity of Personality Measures," Personnel Assessment and Decisions: Number 3 : Iss. 1 , Article 3. DOI: https://doi.org/10.25035/pad.2017.003

Available at: https://scholarworks.bgsu.edu/pad/vol3/iss1/3

This Main Article is brought to you for free and open access by the Journals at ScholarWorks@BGSU. It has been accepted for inclusion in Personnel Assessment and Decisions by an authorized editor of ScholarWorks@BGSU. 


\title{
Using O*NET TO DEVELOP A Framework of Job Characteristics to Potentially Improve the Predictive Validity of Personality Measures
}

\author{
Jeremy Burrus ${ }^{1}$ and Jason D. Way ${ }^{2}$ \\ 1. Professional Examination Service \\ 2. ACT, Inc.
}

ABSTRACT

It has long been theorized that we can improve prediction of job-related behavior from measures of personality by identifying job characteristics that allow for the expression of individual differences (e.g., Mischel, 1968). Using O*NET data, the current paper develops a framework for job characteristics that could improve the extent to which we can predict behavior from personality. More specifically, it investigates relationships between work styles, generalized work activities, and work context variables. Job characteristics varied in importance as a function of four work styles composites: achievement, people orientation, stability, and attention to detail, and the relationships were largely consistent with the tenants of trait activation theory (Tett \& Burnett, 2003). In addition to limitations and future directions, the discussion section contains implications of the current study for practitioners, including implications for hiring practices and job placement.

ONET, personality, validity, assessment
People vary on a number of characteristics that affect their behavior and performance at work. Some of these individual differences include cognitive ability (Schmidt \& Hunter, 1998), interests (Nye, Su, Rounds, \& Drasgow, 2012), and integrity (Ones, Viswesvaran, \& Schmidt, 1993). Additionally, several meta-analyses have demonstrated that personality factors are valid predictors of various measures of job performance (see Sackett \& Walmsley, 2014 for a review). Personality is "the system of enduring, inner characteristics of individuals that contributes to consistency in their thoughts, feelings, and behavior" (Leary, 2005, p. 3). Considerable research has found that personality can be grouped into five broad factors. These "Big Five" factors of personality are: (a) extraversion (e.g., tendency to be sociable), (b) agreeableness (e.g., tendency to get along with others), (c) conscientiousness (e.g., tendency to be organized and hard working), (d) emotional stability (e.g., tendency to be free from anxiety and worry), and (e) openness to experience (e.g., tendency to be imaginative and creative). More recently, other research has suggested that a sixth factor also frequently emerges, honesty-humility (Ashton \& Lee, 2007).

The purpose of this study is to develop an empirically informed theoretical framework that takes job character- istics more fully into account in an attempt to maximize personality's predictive validity. Because O*NET does not have ratings of traditional personality models, this study will use the $\mathrm{O}^{*} \mathrm{NET}$ analogue of work styles to represent personality. The use of the O*NET work styles variables in investigating the personality factors that are important to work performance is not unprecedented. For example, Sackett and Walmsley (2014) recently summarized the importance ratings for O*NET work styles across job zone, using Hough and Ones' (2001) taxonomy to crosswalk each work style to its Big Five equivalent, stating "We found this to be a simple matching procedure with little judgment involved, and discussion was needed to resolve differences in just two instances." (p. 544). The authors found that all Big Five factors were represented by the work styles inventory (although extraversion only appeared as part of a composite variable for two work styles).

It has long been theorized that behavior is a function of the person and the environment (Lewin, 1935), and one way to account for this interaction is through situational strength ("implicit or explicit cues provided by external entities regarding the desirability of potential behaviors"; Meyer,

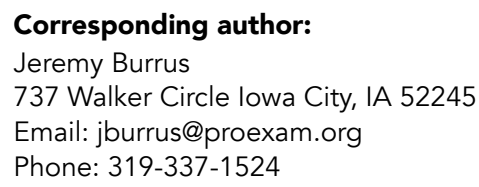


Dalal, \& Hermida, 2010, p. 122). Strong situations provide cues about behavioral desirability. For instance, most people know that speaking loudly is not appropriate at a library (a strong situation), and thus even a very extraverted person is likely to remain quiet while visiting one. In contrast, the extent to which loud talking is appropriate at the mall (a weak situation) is less clear. In that situation, it is likely that extraverts will talk more loudly than introverts.

One theory that has expanded upon the idea of situational strength is Trait Activation Theory (Tett \& Burnett, 2003). The theory states that two factors influence whether a personality trait is expressed in a situation. First, situational strength affects the expression of personality traits as described above. Second, a trait will be expressed to the extent that it is relevant to the situation at hand. For example, extraversion is more relevant to team activities than to solo activities, and thus this trait should predict performance in those situations. Trait-relevant cues can come from three sources: the organization (e.g., my organization is very team oriented), social (e.g., the people I work with on a daily basis are very team oriented), and tasks (e.g., the project on which I am currently working requires me to work with others). Thus, the activated trait is influenced by the relevance of the situation, and the extent to which the activated trait is expressed is influenced by the strength of the situation.

\section{Occupational Information Network $(\mathbf{O} * \mathbf{N E T})$}

One way to develop such a theoretical framework would be to analyze a database that includes information on both characteristics of work situations and the extent to which personality is important for specific jobs. Fortunately, such a database exists in the Occupational Information Network (O*NET; Peterson, Mumford, Borman, Jeanneret, \& Fleishman, 1999). O*NET is an extensive job analysis of over 900 jobs conducted by the U.S. Department of Labor. O*NET provides job-specific information on the importance and/or level of several worker characteristics, worker requirements, experience requirements, occupational requirements, workforce characteristics, and other occupation-specific information. Most of the ratings are made by either job incumbents or by occupational analysts (people who are knowledgeable about job analysis) on 5(for importance ratings) or 7-point (for level ratings) scales. A more detailed description of the $\mathrm{O}^{*} \mathrm{NET}$ data used in the current study is provided in the method section below.

Recently, Judge and Zapata (2015) conducted a meta-analysis investigating the validity of Big Five personality traits in predicting job performance as a function of situation strength and trait activation. Occupations were classified along situation strength and trait activation variables by coding $\mathrm{O}$ *NET context items as informed by theories on the dimensions of situational strength and trait activation (Meyer et al., 2010; Tett \& Burnett, 2003). Situa- tional strength was broadly defined as situational processthe extent that one has freedom in how they perform their work, and situational outcomes - the extent that one's work products present strong demands. Trait activation components were independence in completing work, attention to detail requirements, social skills requirements, level of competition requirements, innovation/creativity requirements, and dealing with unpleasant or angry people. The authors found that situational process positively predicted personality-job performance relationships for all of the Big Five personality factors, whereas situational outcomes negatively predicted the personality job-performance relationship for only agreeableness and openness. Furthermore, trait activation components tended to predict the personality job-performance relationship of theoretically meaningful ways. To provide a few examples, the relationship for conscientiousness was predicted by independence in completing work, emotional stability was predicted by dealing with unpleasant or angry people, extraversion was predicted by social skills, agreeableness was negatively predicted by competition, and openness was predicted by innovation/creativity. This study thus provided evidence that the predictive power of personality traits varies widely as a function of occupational characteristics.

\section{The Current Study}

Recall that trait activation theory (Tett \& Burnett, 2003) states that situational strength and trait relevance influences the expression of personality in jobs. The use of job-specific information from $\mathrm{O} * \mathrm{NET}$ should provide some information about situational strength and trait activation information for each occupation. To develop a framework of job characteristics that can help us learn when personality measures could be more predictive of job behaviors and performance, we examined the current $\mathrm{O} * \mathrm{NET}$ database (version 19.0) using both empirical and rational methods. The goal was to develop a short list of work contexts and/ or activities that are the most predictive of the importance ratings for personality (i.e., O*NET work styles) among the majority of jobs in the U.S. This list of contexts and/or activities can then be validated in future studies in which predictive validity coefficients of personality measures are compared as a function of these contexts and activities. One important difference between our study and Judge and Zapata's meta-analysis is that whereas Judge and Zapata used a top-down theoretical approach in identifying situational strength and trait activation variables, we use more of a bottom-up approach, attempting to first combine $\mathrm{O} * \mathrm{NET}$ variables in meaningful ways and examining their ability to predict work style ratings before settling on our final list of occupational characteristics. Thus, our final list is different than, but conceptually similar to, their list of factors.

The current study bears some resemblance to "synthetic" validation approaches (e.g., Scherbaum, 2005), which 
involve several steps, including (generally): conducting job analyses to identify components of jobs that may be common across several jobs, measuring important predictors (often personality traits) and job performance outcomes, and choosing the most valid predictors of job components identified by job analyses (Johnson \& Carter, 2010). In theory, these predictors should thus be valid predictors for any job that contains the job components identified, and the validity of tests that measure these predictors should be similar across job domains as long as they include these components. Some extant research evidence suggests that validity coefficients produced through synthetic validation are similar to coefficients produced through local validity studies (Johnson \& Carter, 2010; Peterson, Wise, Arabian, \& Hoffman, 2001).

\section{METHODS}

\section{Database}

O*NET database 19.0 (released in July 2014) was used in the current study. Because these data are at the job level (one rating per construct per job), using all ratings from all jobs may lead to misleading results. For example, ratings from a job that employs 560 people nationwide (e.g., private household cooks) will receive the same weight in the analysis as a job that employs well over 4,000,000 people (e.g., retail salespersons). Because the point of the current analysis was to identify job characteristics that would affect the predictive validity of personality measures for jobs that employ the most people, the analysis was restricted to the most frequently held jobs that cumulatively employed $70 \%$ of the people in the U.S. This was done by merging the May 2014 employment data from the Bureau of Labor Statistics (http://www.bls.gov/oes/) into the database and selecting jobs that employed $70 \%$ of the U.S. workforce. This eliminated 771 jobs and resulted in a sample of 117 jobs (see Appendix).

\section{Measures}

Three sets of O*NET ratings were used in the current analysis. First, work styles ratings were used as the measure of personality. O*NET uses the term "work styles," rather than "personality," to emphasize personal characteristics that are occupationally related (Tippins \& Hilton, 2010, p. 29). There are 16 Work Styles dimensions. Each is rated on importance by job incumbents on scales from 1 (not important) to 5 (extremely important). An example item is, "How important is ACHIEVEMENT/EFFORT to the performance of your current job?"

Second, Generalized Work Activities (GWAs) were used as one set of job characteristics. GWAs are "underlying behavioral components of tasks" (Tippins \& Hilton, 2010, p. 34). There are 41 GWAs. They are also rated on importance by job incumbents on an Importance scale that is the same as that used for work styles. Additionally, they are rated on Level by job incumbents on a 7-point scale. An example item is, "What level of GETTING INFORMATION is needed to perform your current job?" Respondents are provided with three anchors for each of the Level rating scales. For this example, scale point 2 is labeled with "Follow a standard blueprint," scale point 4 is labeled with "Review a budget," and scale point 6 is labeled with "Study international tax laws." Scale point 7 is simply labeled "highest level." The current analysis used the Level items only. Because preliminary analyses indicated that Importance and Level ratings are correlated at .95 , results are likely to be similar regardless of which items are used (Peterson et al., 1999).

Third, Work Contexts were used as a second set of job characteristics. They are physical and social factors that influence the nature of work. There are 57 work contexts. Job incumbents rate each on 5-point scales that are for the most part either frequency or importance scales. One example is frequency scale is, "How often does your current job require face-to-face discussions with individuals and within teams?" with response options of 1 (Never), 2 (Once a year or more but not every month), 3 (Once a month or more but not every week), 4 (Once a week or more but not every day), and 5 (Every day). An example importance item is, "How important are interactions that require you to work with or contribute to a work group or team to perform your current job?" The 5-point response scale is identical to the scale used for work styles.

\section{Analysis Plan}

The ultimate goal of the data analysis was to reduce the 114 variables to a manageable number in two steps that maximizes the prediction of personality importance. The first step was to attempt to reduce the number of variables in the analysis by creating summed scales. Because a principal component analysis did not produce interpretable solutions for work styles and work contexts, we used a rational approach based on item intercorrelations. For GWAs, a principal component analysis did produce an interpretable solution, although expert judgment had to be used in the placement of several items.

The second step was to regress the Work Styles scales on the remaining Work Context and GWA scales to examine which scales predict work styles while simultaneously controlling for other scales.

The third step was to enter only the final retained variables into another regression to examine the reduction in $R^{2}$ the resulted as a result of reducing the number of predictors in the model. 


\section{RESULTS}

\section{Work Styles Sum Scale Development}

A principal component analysis with varimax rotation did not reveal an easily interpretable solution. Thus, a rational approach based on the authors independently examining patterns of item intercorrelations (presented in Table 1) was used to develop sum scales. This resulted in 100\% agreement in item assignments into four sum scales: Achievement (average interitem $r=.63 ; \alpha=.94$ ); People Orientation (average interitem $r=.75 ; \alpha=.91)$; Stability and $(r=$ .72); Attention to Detail (average interitem $r=.55 ; \alpha=.88$ ). As a comparison, the average inter-item correlation of all Work Styles scales was .49.

\section{GWA Sum Scale Development}

A principal component analysis with varimax rotation on the GWA items revealed an interpretable four-factor structure (see Table 2$)^{1}$ : Working with Information $(\alpha=$ .98), Leading, Motivating, and Coordinating $(\alpha=.97)$, Manual and Physical Activities $(\alpha=.93)$, and Helping Others $(r=.53)$.

\section{Work Contexts Sum Scale Development}

As with Work Styles, a principal component analysis with varimax rotation did not reveal an easily interpretable solution. A $57 \times 57$ correlation matrix would be extremely difficult to interpret, so as a first step, to immediately greatly reduce the number of context variables, all variables that asked about the physical requirements of the job (34) were eliminated. Most of the physical requirement items (e.g., "In your current job, how often are you exposed to whole body vibration [like operating a jackhammer or earth moving equipment]?") did not seem as relevant to personality variables as the other items. A correlation table for the remaining 22 variables can be found in Table 3 .

There were several context variables that were not highly correlated with other variables and that, after initial review by the authors, seemed to stand on their own (i.e., they could not be easily grouped with other variables). These were thus retained as 1-item measures. These include: the amount of public speaking, the amount of in-person communication, the amount of customer interaction, the importance of being accurate, the level of competition

\footnotetext{
1 Because running a principal component analysis on 41 variables with a sample of 117 violates the generally recommended 10:1 case to variable ratio for principal component analyses, we also ran this analysis including all jobs in the database. The resulting structure was nearly identical. Two exceptions were assisting and caring for others, which formed its own $5^{\text {th }}$ factor, and selling or influencing others, which loaded more highly on the helping others factor than on the leading, motivating, and coordinating factor (although it did still load highly on this factor). A rational inspection of these two activities, however, suggests that it is not unreasonable to keep them in their original factors. We also reran principal component analyses on the work style and work context ratings using all jobs in the database. This analysis again failed to produce an easily interpretable solution.
}

present, the amount of time pressure present, and the level of automation present. After this, the two authors again assigned items to scales independently based on patterns of item intercorrelations, which also resulted in $100 \%$ agreement in these item assignments to five scales (item assignments shown in Table 3): Not-in-person Communication (average inter-item $r=.76 ; \alpha=.88$ ), Teamwork (average inter-item $r=.59 ; \alpha=.79$ ), Conflict (average inter-item $r=$ $.70 ; \alpha=.87)$, Consequences of Work $(\mathrm{r}=.65)$, and Lack of Constraints $(r=.81)$. The final list of Work Styles, GWA, and context variables used in the remainder of the study is provided in Table 4. As a comparison, the average interitem correlation of all Work Context scales was .33.

\section{Regression Analyses Predicting Work Styles}

We next regressed each of the four Work Styles sum scales on the retained GWA and Work Context sum scales, with the plan of retaining the predictors that remained significant while simultaneously controlling for the others. Results are presented in Table 5. Consistent with the meta-analysis of Judge and Zapata (2015), the importance of personality varied as a function of job characteristics that appeared to vary on both situational strength process (the extent that one has freedom in how they perform their work) and trait activation (the extent to which trait-consistent behavior is desirable in a situation) dimensions. Furthermore, and also largely consistent with the findings of Judge and Zapata, several differences emerged between personality dimensions, many of which make theoretical sense.

Situational strength process job characteristics that significantly predicted achievement included degree of automation $(\beta=-.15)$ and lack of constraints $(\beta=.33)$. Trait activation job characteristics that significantly predicted achievement were not-in-person communication $(\beta=.20)$ and working with information $(\beta=.47)$.

The situational strength process job characteristics that significantly predicted people orientation was manual and physical activities $(\beta=-.20)$. Trait activation job characteristics that significantly predicted people orientation was face-to-face discussions $(\beta=.12)$; level of competition $(\beta=$ -.27); teamwork ( $\beta=.11)$; leading, motivation, and coordinating $(\beta=-.23)$; and helping others $(\beta=.59)$.

The situational strength process job characteristics that significantly predicted stability was manual and physical activities $(\beta=-.21)$. Trait activation job characteristics that significantly predicted stability were level of competition ( $\beta$ $=-.22)$, conflict $(\beta=.25)$, and working with information $(\beta$ $=.38$ ).

Finally, situational strength process job characteristics that significantly predicted attention to detail were degree of automation $(\beta=-.13)$ and lack of constraints $(\beta=.17)$. Trait activation job characteristics that significantly predicted attention to detail were level of competition $(\beta=-.25)$, 
TABLE 1.

Work Styles Item Intercorrelations

\begin{tabular}{|c|c|c|c|c|c|c|c|c|c|c|c|c|c|c|c|}
\hline & 1 & 2 & 3 & 4 & 5 & 6 & 7 & 8 & 9 & 10 & 11 & 12 & 13 & 14 & 15 \\
\hline \multicolumn{16}{|l|}{ (1) Achievement effort ${ }^{a}$} \\
\hline (2) Persistence ${ }^{a}$ & $.87 *$ & & & & & & & & & & & & & & \\
\hline (3) Initiative $\mathrm{a}^{\mathrm{a}}$ & $.82 *$ & $.87 *$ & & & & & & & & & & & & & \\
\hline (4) Leadership ${ }^{a}$ & $.70^{*}$ & $.77 *$ & $.82 *$ & & & & & & & & & & & & \\
\hline (5) Cooperation ${ }^{\mathrm{b}}$ & $.48 *$ & $.48^{*}$ & $.55^{*}$ & $.54 *$ & & & & & & & & & & & \\
\hline (6) Concern for others ${ }^{b}$ & $.36^{*}$ & $.38^{*}$ & $.41^{*}$ & $.49^{*}$ & $.75^{*}$ & & & & & & & & & & \\
\hline (7) Social orientation ${ }^{b}$ & $.29 *$ & $.30 *$ & $.34 *$ & $.45^{*}$ & $.75 *$ & $.84 *$ & & & & & & & & & \\
\hline (8) Self-control ${ }^{\mathrm{b}}$ & $.41 *$ & $.47 *$ & $.47 *$ & $.52 *$ & $.72 *$ & $.79 *$ & $.76^{*}$ & & & & & & & & \\
\hline (9) Stress tolerance ${ }^{c}$ & $.61 *$ & $.63^{*}$ & $.63^{*}$ & $.62 *$ & $.69 *$ & $.69^{*}$ & $.68^{*}$ & $.86^{*}$ & & & & & & & \\
\hline $\begin{array}{l}\text { (10) Adaptability/ } \\
\text { flexibility }^{c}\end{array}$ & $.64 *$ & $.68^{*}$ & $.74 *$ & $.69 *$ & $.72 *$ & $.65^{*}$ & $.57^{*}$ & $.70 *$ & $.76^{*}$ & & & & & & \\
\hline (11) Dependability ${ }^{\mathrm{d}}$ & $.59 *$ & $.63^{*}$ & $.68^{*}$ & $.62 *$ & $.71 *$ & $.67 *$ & $.56^{*}$ & $.72 *$ & $.76^{*}$ & $.82 *$ & & & & & \\
\hline (12) Attention to detail ${ }^{\mathrm{d}}$ & $.63 *$ & $.62 *$ & $.65^{*}$ & $.48^{*}$ & $.49^{*}$ & $.38^{*}$ & $.26^{*}$ & $.39 *$ & $.53 *$ & $.63^{*}$ & $.72 *$ & & & & \\
\hline (13) Integrity ${ }^{d}$ & $.68 *$ & $.68^{*}$ & $.71 *$ & $.62 *$ & $.67 *$ & $.56^{*}$ & $.49 *$ & $.69^{*}$ & $.74 *$ & $.75^{*}$ & $.81 *$ & $.69^{*}$ & & & \\
\hline (14) Independence ${ }^{a}$ & $.58 *$ & $.60^{*}$ & $.66^{*}$ & $.59 *$ & $.52 *$ & $.56^{*}$ & $.45^{*}$ & $.53 *$ & $.55^{*}$ & $.63^{*}$ & $.68 *$ & $.62 *$ & $.68^{*}$ & & \\
\hline (15) Innovation ${ }^{a}$ & $.55^{*}$ & $.62 *$ & $.72 *$ & $.69^{*}$ & $.45 *$ & $.39 *$ & $.29 *$ & $.36^{*}$ & $.40^{*}$ & $.64 *$ & $.56^{*}$ & $.50^{*}$ & $.52 *$ & $.66^{*}$ & \\
\hline $\begin{array}{l}\text { (16) Analytical } \\
\text { thinking }^{\mathrm{a}}\end{array}$ & $.80^{*}$ & $.83^{*}$ & $.81 *$ & $.71 *$ & $.40 *$ & $.26^{*}$ & .13 & $.32 *$ & $.53 *$ & $.65^{*}$ & $.62 *$ & $.72 *$ & $.67^{*}$ & $.60 *$ & $.70^{*}$ \\
\hline
\end{tabular}

Note. ${ }^{*} p<.01 . \mathrm{a}=$ assigned to Achievement sum scale, $\mathrm{b}=$ assigned to People Orientation sum scale, $\mathrm{c}=$ assigned to Stability sum scale, $\mathrm{d}=$ assigned to Attention to Detail sum scale

TABLE 2.

GWA Factor Loadings

\begin{tabular}{|c|c|c|c|c|}
\hline \multirow[b]{2}{*}{ GWA Characteristics } & \multicolumn{4}{|c|}{ Factor } \\
\hline & 1 & 2 & 3 & 4 \\
\hline Processing information & .88 & .31 & -.15 & -.02 \\
\hline Updating and using relevant knowledge & .86 & .38 & -.01 & .04 \\
\hline Analyzing data or information & .84 & .43 & -.16 & -.06 \\
\hline Documenting/recording information & .84 & .30 & -.04 & .24 \\
\hline Interpreting the meaning of information for others & .81 & .43 & -.10 & .06 \\
\hline Making decisions and solving problems & .80 & .45 & -.05 & .14 \\
\hline Getting information & .80 & .43 & -.23 & .12 \\
\hline Evaluating information to determine compliance with standards & .79 & .35 & -.05 & .17 \\
\hline Identifying objects, actions, and events & .78 & .25 & .02 & .35 \\
\hline Monitor processes, materials, or surroundings & .74 & .21 & .35 & .40 \\
\hline Interacting with computers & .69 & .29 & -.26 & -.25 \\
\hline Thinking creatively & 67 & .52 & .01 & -.15 \\
\hline Communicating with supervisors, peers, or subordinates & .66 & .59 & -.12 & .09 \\
\hline Estimating the quantifiable characteristics of products, events, or information & .66 & .40 & .40 & -.03 \\
\hline Organizing, planning, and prioritizing work & .64 & .60 & -.15 & -.04 \\
\hline Judging the qualities of things, services, or people & .63 & .53 & .14 & .23 \\
\hline Provide consultation and advice to others & .63 & .67 & -.06 & .02 \\
\hline Developing objectives and strategies & .63 & 67 & -.06 & -.01 \\
\hline Performing administrative activities & .57 & .53 & -.29 & .17 \\
\hline Scheduling work and activities & .55 & .71 & .02 & -.03 \\
\hline Communicating with persons outside organization & .52 & .56 & -.36 & .13 \\
\hline Establishing and maintaining interpersonal relationships & .48 & .59 & -.31 & .26 \\
\hline Training and teaching others & .46 & .66 & .11 & .26 \\
\hline Developing and building teams & .40 & .82 & .07 & .08 \\
\hline Coaching and developing others & .37 & .80 & -.01 & .20 \\
\hline Monitoring and controlling resources & .35 & .77 & .13 & -.03 \\
\hline
\end{tabular}




\section{(Table 2 continued)}

Guiding, directing, and motivating subordinates

Resolving conflicts and negotiating with others

Staffing organizational units

Coordinating the work and activities of others

Assisting and caring for others

Inspecting equipment, structures, or material

Drafting, laying out, and specifying technical devices, parts, and equipment

Selling or influencing others

Repairing and maintaining electronic equipment

Performing for or working directly with the public

Controlling machines and processes

Repairing and maintaining mechanical equipment

Operating vehicles, mechanized devices, or equipment

Performing general physical activities

Handling and moving objects

\begin{tabular}{l|l|ll}
.3 & .86 & .11 & .11 \\
.34 & .72 & -.22 & .30 \\
.33 & .82 & -.00 & .15 \\
.32 & .84 & .12 & .03 \\
\cline { 4 - 4 } .30 & .12 & .11 & .83 \\
\cline { 3 - 4 } .27 & .04 & .83 & .20 \\
.19 & .27 & .74 & -.35 \\
\cline { 3 - 4 } .16 & .67 & -.26 & -.04 \\
.05 & .05 & .79 & -.25 \\
\hline .02 & .25 & -.18 & .74 \\
\cline { 3 - 4 }-.03 & -.12 & .89 & .02 \\
-.13 & -.03 & .92 & -.17 \\
-.15 & -.04 & .81 & -.01 \\
-.33 & -.09 & .82 & .27 \\
-.38 & -.19 & .80 & .22 \\
\hline
\end{tabular}

Note. These loadings are based on varimax rotation. Factor to which descriptors were placed are boxed. F1 = Working with Information; F2 = Leading, Motivating, and Coordinating; F3 = Manual and Physical Activities; F4 = Helping Others

TABLE 3.

Work Context Item Intercorrelations

\begin{tabular}{|c|c|c|c|c|c|c|c|c|c|c|c|c|c|c|c|c|c|c|c|c|c|}
\hline & 1 & 2 & 3 & 4 & 5 & 6 & 7 & 8 & 9 & 10 & 11 & 12 & 13 & 14 & 15 & 16 & 17 & 18 & 19 & 20 & 21 \\
\hline (1) Public speaking & & & & & & & & & & & & & & & & & & & & & \\
\hline (2) Telephone $e^{a}$ & $.24 * *$ & & & & & & & & & & & & & & & & & & & & \\
\hline (3) Electronic mail ${ }^{\mathrm{a}}$ & $.43 * *$ & $.77 * *$ & & & & & & & & & & & & & & & & & & & \\
\hline (4) Letters and $\mathrm{memos}^{\mathrm{a}}$ & $.37 * *$ & $.74 * *$ & $.78^{* *}$ & & & & & & & & & & & & & & & & & & \\
\hline (5) Face-to-face discu & $.35^{* * *}$ & $.50^{* *}$ & $.46^{* *}$ & $46 * *$ & & & & & & & & & & & & & & & & & \\
\hline
\end{tabular}

sions

(6) Contact with others $\quad .25 * * .49 * * .29 * * .44 * * .39 * *$

(7) Work with work group $.32^{* *} .37^{* *} .30^{* *} .36^{* *} .47^{* *} .52^{* *}$

or team ${ }^{\mathrm{b}}$

(8) Deal with external cus- $.31 * * .61 * * .39^{* *} .53^{* *} .31 * * .68^{* *} .42 * *$

tomers

(9) Coordinate or lead oth- $.46^{* *} .40^{* *} .44 * * .45^{* *} .48^{* *} .35^{* *} .72 * * .40 * *$

$\mathrm{ers}^{\mathrm{b}}$

(10) Responsibility for $.24 * * .29^{* *} .26^{* *} .25^{* *} .41^{* *} .12 \quad .45^{* *} .15 \quad .60^{* *}$

outcomes and results $^{\mathrm{b}}$

(11) Frequency of conflict $.46^{* *} .41^{* *} .33^{* *} .50^{* *} .43^{* *} .51^{* *} .34^{* *} .54^{* *} .45^{* *} .27^{* *}$

situations ${ }^{\mathrm{c}}$

(12) Deal with unpleasant $.13 \quad .26^{* *} .02 \quad .25^{* *} .19^{*} \quad .57^{* *} .28^{* *} .57^{* *} .22^{* *} .09 \quad .73^{* *}$

or angry people ${ }^{\mathrm{c}}$

(13) Deal with physically $.27^{* *} .12 \quad-.03 \quad .17^{*} \quad .15 \quad .32^{* *} .27^{* *} .35^{* *} .27^{* *} .09 \quad .65^{* *} .73^{* *}$

aggressive people

(14) Consequence of error ${ }^{\mathrm{d}} .06 \quad .30^{* *} .21^{* *} .28^{* *} .33^{* *} .04 \quad .20^{* *} .18^{*} \quad .32^{* *} .43^{* *} .26^{* *} .15 \quad .30^{* *}$

(15) Impact of decisions $.33^{* *} .58^{* *} .49^{* *} .58^{* *} .45^{* *} .35^{* *} .36^{* *} .50^{* *} .47^{* *} .52^{* *} .51^{* *} .25^{* *} .25^{* *} .65^{* *}$

on coworkers or company

results $^{\mathrm{d}}$

(16) Frequency of decision $.27^{* *} .51^{* *} .39^{* *} .51^{* *} .47^{* *} .40^{* *} .30^{* *} .51^{* *} .34^{* *} .41^{* *} .54^{* *} .35^{* *} .25^{* *} .55^{* *} .89^{* *}$

making

(17) Freedom to make de- $.38^{* *} .54^{* *} .50^{* *} .55^{* *} .49^{* *} .31^{* *} .31^{* *} .39^{* *} .43^{* *} .45^{* *} .39^{* *} .07 \quad .10 \quad .44^{* *} .75^{* *} .68^{* *}$

cisions $^{\mathrm{e}}$

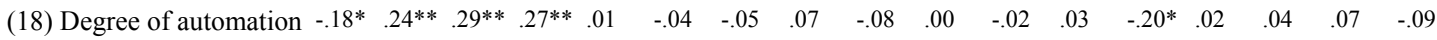

(19) Importance of being $-.12 \quad .44^{* *} .39^{* *} .38^{* *} .30^{* *} .27^{* *} .21^{* *} .26^{* *} .18^{*} \quad .31^{* *} .15 \quad .16^{*} \quad .03 \quad .50^{* *} .53^{* *} .50^{* *} .35^{* *} .36^{* *}$

exact or accurate

(20) Structured versus un- $.34 * * .67^{* *} .65^{* *} .65^{* *} .49^{* *} .35^{* *} .36^{* *} .41^{* *} .45^{* *} .38^{* *} .31^{* *} .03 \quad-.01 \quad .32^{* *} .65^{* *} .59^{* *} .81^{* *} .01 \quad .37^{* *}$ structured work ${ }^{\mathrm{e}}$

(21) Level of competition $\quad .18^{*} \quad .47^{* *} .48^{* *} .34^{* *} .27^{* *} .03 \quad .10 \quad .27^{* *} .25^{* *} .38^{* *} .13 \quad-.09 \quad-.21^{* *} .38^{* *} .56^{* *} .47^{* *} .46^{* *} .31^{* *} .47^{* *} .45^{* *}$

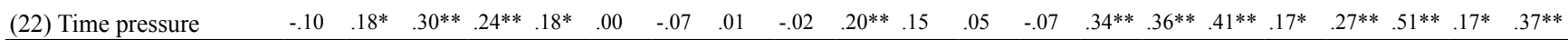

Note. ${ }^{* *} p<.01 ;{ }^{*} p<.05$. All correlations with an absolute value above .166 are significant $(p<.05)$. a=assigned to Not-in-person communication sum scale, $\mathrm{b}=$ assigned to Teamwork sum scale, $\mathrm{c}=$ assigned to Conflict sum scale, $\mathrm{d}=$ assigned to Consequences of Work sum scale, $\mathrm{e}=\mathrm{assigned}$ to Lack of Constraints sum scale 
TABLE 4.

Work Styles, GWA, and Context Scales Investigated in the Study

\begin{tabular}{lll}
\hline \multicolumn{1}{c}{ Work Styles } & \multicolumn{1}{c}{ GWAs } & \multicolumn{1}{c}{ Contexts } \\
\hline Achievement & Working with information & Amount of public speaking \\
People orientation & Leading, motivating, and coordinating & Amount of in-person communication \\
Stability & Manual and physical activities & Amount of customer interaction \\
Attention to detail & Helping others & Importance of being accurate \\
& & Level of competition present \\
& & Amount of time pressure present \\
& & Level of automation present \\
& & Not-in-person communication \\
& & Teamwork \\
& Conflict \\
& Consequences of work \\
\hline
\end{tabular}

not-in-person communication $(\beta=.33)$, and working with information $(\beta=.38)$.

A second set of regressions was conducted with only the final set of job characteristics entered to examine the extent to which the variance explained is reduced by the reduction of variables. As can be seen in comparing Table 5 to Tables 6 through 9, this reduction was small to moderate. The $R^{2}$ for the reduced set of job characteristics for achievement importance was .74 (down from .76), $R^{2}$ for people orientation was .74 (down from .76), $R^{2}$ for stability.58 (down from .67), and $R^{2}$ for attention to detail was .63 (down from .69).

\section{Example Job Profiles}

To provide a few illustrative examples of how jobs range on these job characteristics, job profiles can be found in Figures 1 to 4 . To create these profiles, scores were first standardized on each characteristic (characteristics were not on the same scale because scales consisted of different numbers of items). Each profile displays one job that is high, and one that is low, on terms of rated each of the four work styles dimensions.

The profiles provide illustrative examples of how job characteristics vary as a function of personality variables. Characteristics to the left of the dotted line represent situational strength process characteristics whereas characteristics to the right of the dotted line represent trait activation characteristics. To provide one example, Figure 1 shows that a job that demands high achievement (urologists) has a greater lack of constraints, more not-in-person communication, and a greater amount of working with information (but a lower degree of automation) than a job with lower achievement demands. Thus suggests, along with the regression analysis, that measures of achievement should be predictive of performance in jobs with the situational strength process characteristics of low degree of automation and lack of constraints, and with the trait activation charac- teristics of high not-in-person communication and working with information.

\section{DISCUSSION}

In the current paper, both rational and empirical approaches were used to reduce the O*NET GWA and work context variables into a manageable set of job characteristics that could help workforce researchers determine when, and which, personality dimensions will be most predictive of job performance. Consistent with the meta-analysis of Judge and Zapata (2015), we found that both situational strength process and trait activation relevant job characteristics predicted the importance of personality. Recall that situational strength process is represented by the extent that one has freedom in how they perform their work. In the current study, this is represented by job characteristics such as degree of automation, lack of constraints, and number of manual and physical activities. Consistent with the theory, lower automation, number of manual and physical activities, and fewer constraints are related to higher personality importance. Furthermore, trait activation is represented by the extent to which trait-consistent behavior is desirable in a situation. In the current study, this is reflected by variables such as face-to-face discussion and teamwork (related to our people orientation scale), conflict (related to stability), working with information (related to achievement), and helping others (related to people orientation).

\section{Limitations}

This study has several limitations. One limitation concerns the self-report nature of the O*NET data. That is, job incumbents rated their impression of the importance and level of each of these variables. It is well-known that self-reported skill ratings are subject to several judgmental biases (Dunning, Heath, \& Suls, 2004), and there is no reason to believe that $\mathrm{O} * \mathrm{NET}$ ratings are not also subject to 
TABLE 5.

Regression Predicting Work Styles with Job Characteristics

\begin{tabular}{|c|c|c|c|c|c|c|c|c|c|c|c|c|}
\hline \multirow[b]{3}{*}{ Job characteristic } & \multicolumn{12}{|c|}{ Work Styles } \\
\hline & \multicolumn{3}{|c|}{ Achievement } & \multicolumn{3}{|c|}{ People orientation } & \multicolumn{3}{|c|}{ Stability } & \multicolumn{3}{|c|}{ Attention to detail } \\
\hline & $\mathrm{B}$ & SE B & $\beta$ & $\mathrm{B}$ & SE B & $\beta$ & $\mathrm{B}$ & SE B & $\beta$ & $\mathrm{B}$ & SE B & $\beta$ \\
\hline Public speaking & .38 & .26 & .08 & .23 & .14 & .09 & .09 & .08 & .07 & -.01 & .10 & -.01 \\
\hline Face-to-face discussions & .37 & .54 & .04 & .71 & .30 & $.12 *$ & .31 & .17 & .11 & .39 & .21 & .11 \\
\hline Deal with external customers & -.53 & .28 & -.13 & .00 & .16 & .00 & .01 & .09 & .01 & .01 & .11 & .01 \\
\hline Importance of being accurate & -.24 & .39 & -.04 & -.10 & .21 & -.03 & -.06 & .12 & -.04 & .26 & .15 & .13 \\
\hline Level of competition & .12 & .31 & .02 & -.76 & .17 & $-.27 * *$ & -.30 & .10 & $-.22 * *$ & -.43 & .12 & $-.25 * *$ \\
\hline Time pressure & .32 & .27 & .06 & .04 & .15 & .01 & .04 & .09 & .03 & .18 & .11 & .10 \\
\hline Degree of automation & -.87 & .31 & $-.15 * *$ & -.11 & .17 & -.04 & -.06 & .10 & -.04 & -.25 & .12 & $-.13 *$ \\
\hline Not-in-person communication & .21 & .10 & $.20 *$ & .05 & .05 & .09 & .04 & .03 & .13 & .11 & .04 & $.33 * *$ \\
\hline Teamwork & .22 & .12 & .10 & .14 & .07 & $.11 *$ & .02 & .04 & .04 & -.07 & .05 & -.09 \\
\hline Conflict & .17 & .11 & .09 & .11 & .06 & .11 & .13 & .04 & $.25^{* *}$ & .00 & .04 & .00 \\
\hline Consequences & -.16 & .18 & -.06 & -.07 & .10 & -.05 & .07 & .06 & .11 & .02 & .07 & .03 \\
\hline Lack of constraints & 1.14 & .23 & $.33 * *$ & .23 & .13 & .12 & .14 & .07 & .16 & .20 & .09 & $.17 *$ \\
\hline Working with information & .11 & .02 & $.47 * *$ & .02 & .01 & .12 & .02 & .01 & $.38 * *$ & .02 & .01 & $.28 *$ \\
\hline Leading, motivating, coordinating & -.02 & .02 & -.10 & -.03 & .01 & $-.23 *$ & -.01 & .01 & -.18 & .00 & .01 & .01 \\
\hline Manual and physical activities & -.04 & .02 & -.10 & -.05 & .01 & $-.20 * *$ & -.02 & .01 & $-.21 * *$ & -.02 & .01 & -.12 \\
\hline Helping others & .00 & .10 & .00 & .42 & .05 & $.59 * *$ & .04 & .03 & .11 & .06 & .04 & .13 \\
\hline$R^{2}\left(\right.$ adjusted $\left.R^{2}\right)$ & & $.76(.74)$ & & & $.77(.75)$ & & & $.67(.64)$ & & & $.69(.66)$ & \\
\hline
\end{tabular}

Note. ${ }^{* *} p<.05$. $* p<.01$.

TABLE 6 .

Regression Predicting Achievement Work Style With Retained Job Characteristics

\begin{tabular}{lccc}
\hline & & Achievement & \\
\cline { 2 - 4 } Job characteristic & $\mathrm{B}$ & SE B & \multicolumn{1}{c}{$\beta$} \\
\hline Degree of automation & -.97 & .26 & $.17^{* *}$ \\
Not-in-person communication & .28 & .07 & $.28^{* *}$ \\
Lack of constraints & 1.04 & .20 & $.30^{* *}$ \\
Working with information & .09 & .01 & $.41^{* *}$ \\
$R^{2}$ (adjusted $R^{2}$ ) & & $.74(.74)$ & \\
\hline
\end{tabular}

Note. $* * p<.01$.

TABLE 7.

Regression Predicting People Orientation Work Style With Retained Job Characteristics

\begin{tabular}{lccc}
\hline & \multicolumn{3}{c}{ People Orientation } \\
\cline { 2 - 4 } Job characteristic & $\mathrm{B}$ & $\mathrm{SE} \mathrm{B}$ & $\beta$ \\
\hline Face-to-face discussions & 1.07 & .29 & $.19^{* *}$ \\
Level of competition & -.80 & .14 & $-.29^{* *}$ \\
Teamwork & .18 & .07 & $.15^{* *}$ \\
Leading, motivating, coordinating & .00 & .01 & -.02 \\
Manual and physical activities & -.06 & .01 & $-.27^{* *}$ \\
Helping others & .47 & .03 & $.65^{* *}$ \\
$R^{2}$ (adjusted $R^{2}$ ) & & $.73(.73)$ & \\
\hline
\end{tabular}

Note. $* * p<.01$.

TABLE 8.

Regression Predicting Stability Work Style With Retained Job Characteristics

\begin{tabular}{lccc}
\hline & & Stability & \\
\cline { 2 - 4 } Job characteristic & $\mathrm{B}$ & $\mathrm{SE} \mathrm{B}$ & \multicolumn{2}{c}{$\beta$} \\
\hline Level of competition & -.22 & .08 & $.16^{* *}$ \\
Conflict & .22 & .03 & $.43^{* *}$ \\
Working with information & .03 & .00 & $.54^{* *}$ \\
Manual and physical activities & -.03 & .01 & $-.24^{* *}$ \\
$R^{2}$ (adjusted $R^{2}$ ) & & $.58(.58)$ & \\
\hline
\end{tabular}

Note. $* * p<.01$. 
TABLE 9.

Regression Predicting Attention to Detail Work Style With Retained Job Characteristics

\begin{tabular}{lccc}
\hline & & Attention to Detail & \\
\cline { 2 - 4 } Job characteristic & $\mathrm{B}$ & SE B & \multicolumn{2}{c}{} \\
\hline Level of competition & -.45 & .11 & $.26^{* *}$ \\
Degree of automation & -.13 & .11 & -.07 \\
Not-in-person communication & .15 & .03 & $.44^{* *}$ \\
Lack of constraints & .27 & .08 & $.24^{* *}$ \\
Working with information & .03 & .01 & $.36^{* *}$ \\
Helping others & .47 & .03 & $.65^{* *}$ \\
$R^{2}$ (adjusted $\left.R^{2}\right)$ & & $.63(.62)$ & \\
\hline
\end{tabular}

Note. $* * p<.01$.

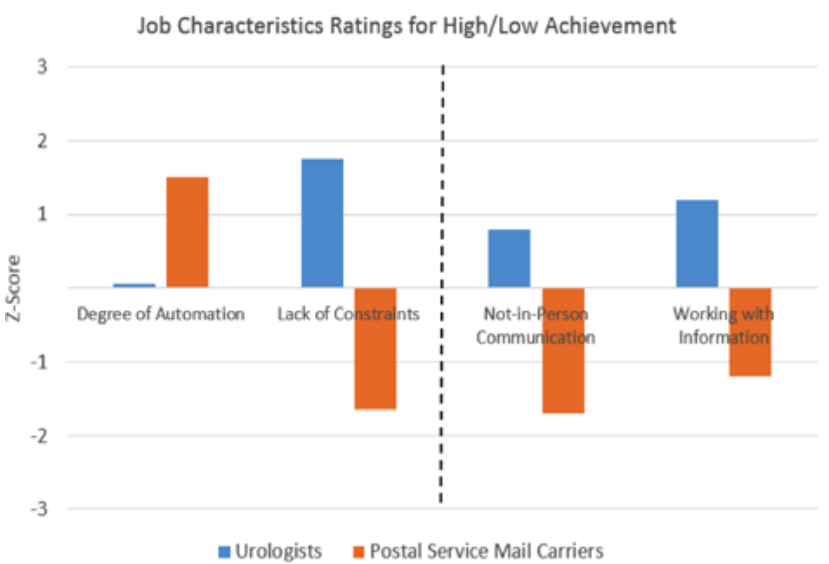

FIGURE 1. Two example job profiles for high/low achievement. Situational strength process characteristics are to the left of the dashed line, trait activation characteristics are to the right of the dashed line. Mean achievement work styles importance means (out of 5): Urologists: 4.68; Postal service mail carriers: 2.62 .

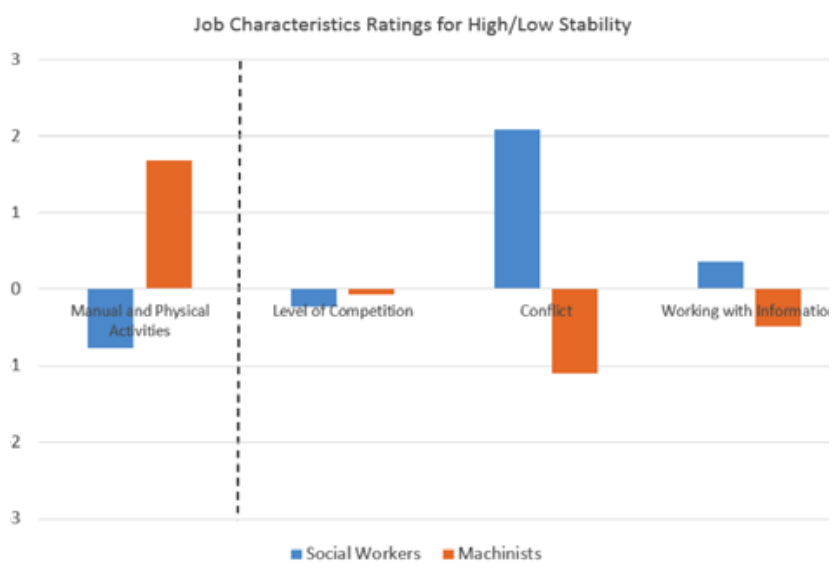

FIGURE 3. Two example job profiles for high/low stability. Situational strength process characteristics are to the left of the dashed line, trait activation characteristics are to the right of the dashed line. Mean stability work styles importance means (out of 5): Social workers: 4.75; Fuel cell engineers: 3.41.

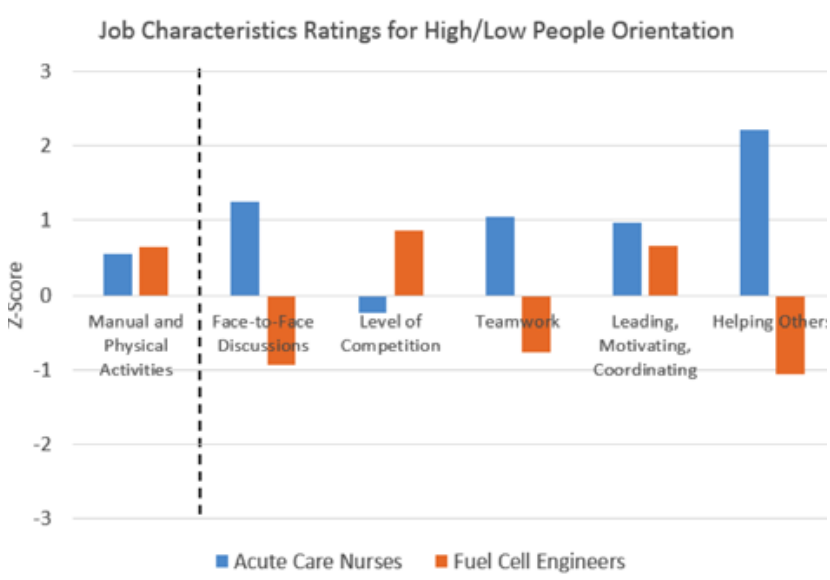

FIGURE 2. Two example job profiles for high/low people orientation. Situational strength process characteristics are to the left of the dashed line, trait activation characteristics are to the right of the dashed line. Mean people orientation work styles importance means (out of 5): Acute care nurses: 4.61; Fuel cell engineers: 3.13.2.62.

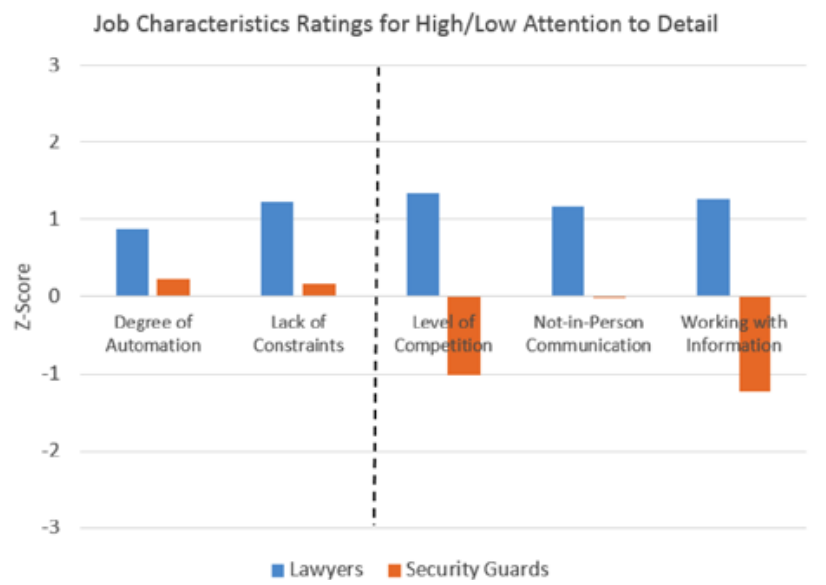

FIGURE 4. Two example job profiles for high/low attention to detail.Situational strength process characteristics are to the left of the dashed line, trait activation characteristics are to the right of the dashed line. Mean attention to detail work styles importance means (out of 5): Lawyers: 4.77; Security guards: 3.31 . 
these biases. Indeed, a brief look at the mean ratings for the 16 work styles shows that mean ratings range from 3.48 to 4.38 , well above the scale midpoint of 3.00. Furthermore, none of the work styles was rated "not important" for any of the jobs in the analysis, with the lowest rating equaling 1.85 .

Another limitation is that the O*NET work styles taxonomy does not fully represent all facets of the Big Five personality traits. Table 10 demonstrates that our achievement variable primarily represented conscientiousness (with some openness), people orientation was primarily represented by agreeableness, stability was primarily represented by emotional stability, and attention to detail was primarily represented by conscientiousness (as indicated by Sackett \& Walmsley's, 2014 crosswalk). Thus, extraversion and openness are not well represented. As such, due to these limitations, the current study cannot be considered a fully comprehensive study on job characteristics and personality.

A third limitation was the use of single- and two-item measures (e.g., our helping others factor) to identify job characteristics. Although the use of some of these measures was unavoidable given the nature of the O*NET database, it would have been preferable to identify job characteristics with longer and more reliable inventories. We do note, however, that Judge and Zapata (2015) used one-item measures to identify job characteristics in their meta-analysis.

Finally, another limitation of the current work concerns the possible ambiguity with which $\mathrm{O} * \mathrm{NET}$ ratings were made. Because they ask only about "importance," it may be unclear for some occupations whether high ratings for importance should be interpreted to mean that possessing the trait should lead to higher or lower performance. This may be one reason we see a couple of relationships that may be interpreted as unexpected (e.g., negative relationship with stability and level of competition, negative relationship with people orientation and leading).

\section{Implications for Practitioners}

There are clear implications for practitioners for the current findings. For instance, this study can inform practitioners' hiring practices. Human resource departments can classify positions within their organizations according to the job characteristics outlined in this paper. This can be done by either consulting the O*NET database or by some other organization-specific method. Next, the personality variables identified in this study can be assessed during the hiring process. Hiring preference should then be given to job candidates who score high on those personality dimensions that are rated as important for jobs within the organization. One clear example is the relationship of the helping others job characteristic and the people orientation work style (see Table 7). Job candidates who score high on an assessment of people orientation should be considered for jobs high on the helping others personality dimension (e.g., registered nurses).

Relatedly, the results of this study can help inform job placement and promotion of workers already in the organization. Theoretically, all workers in a given organization can be assessed with relatively brief measures of each of the four personality dimensions. As with the hiring example, positions within an organization can be classified along the work characteristic dimensions identified in the study. The results can help organizations identify which employees may be a poor fit in their current jobs and be better placed

TABLE 10.

Crosswalk of Work Styles Scales Used in the Current Study With Sackett and Walsmley's (2014) Crosswalk of O*NET Work Styles Ratings to Big Five Personality Factors

\begin{tabular}{llc}
\hline Work styles component & Scale assignment & Sackett \& Walmsley (2014) Big Five coding \\
\hline Achievement effort & Achievement & $\mathrm{C}$ \\
Persistence & Achievement & $\mathrm{C}$ \\
Initiative & Achievement & $\mathrm{C}$ \\
Leadership & Achievement & $\mathrm{C}, \mathrm{EX}, \mathrm{O}$ \\
Cooperation & People orientation & $\mathrm{A}$ \\
Concern for others & People orientation & $\mathrm{A}$ \\
Social orientation & People orientation & EX, A \\
Self-control & People orientation & ES \\
Stress tolerance & Stability & ES \\
Adaptability/flexibility & Stability & O, ES \\
Dependability & Attention to detail & $\mathrm{C}$ \\
Attention to detail & Attention to detail & $\mathrm{C}$ \\
Integrity & Attention to detail & $\mathrm{C}, \mathrm{A}, \mathrm{ES}$ \\
Independence & Achievement & $\mathrm{O}, \mathrm{C}$ \\
Innovation & Achievement & $\mathrm{O}$ \\
Analytical thinking & Achievement & $\mathrm{O}$ \\
\hline
\end{tabular}

Note. $\mathrm{C}=$ conscientiousness, $\mathrm{EX}=$ extraversion, $\mathrm{O}=$ openness to experience, $\mathrm{A}=$ agreeableness, $\mathrm{ES}=$ emotional stability. 
in other positions within the company. For example, employees low in stability might be poorly fit to jobs that are very competitive and may thus be more effective in positions that involve less competition. In addition to placement in to new jobs, other possibilities for improved job performance might be to attempt an intervention designed to improve skills related to stability (e.g., stress management techniques) or to eliminate some of the competitive aspects of their current position.

\section{Future Research}

There is much room for future research in this area. For instance, future research can focus on including the physical environment variables or more jobs in the analysis. Another important area of future research will be to apply this, or a similar, methodology to the $\mathrm{O}^{*}$ NET knowledge, skills, and abilities ratings. These variables have the potential to be just as, if not more, predictive of job performance as personality, especially if matched with specific job characteristics.

Finally, after jobs are grouped, it will be of critical importance to examine whether these job characteristics do indeed help us to better predict job performance with personality assessments. Ideally, during a large-scale data collection effort, one should be able to categorize job along these characteristics and then predict a priori which personality scales should be predictive for specific jobs.

\section{CONCLUSION}

The fields of personality and industrial-organizational psychology have long searched for a way to maximize the prediction of behavior with personality assessments. One idea for doing so that has been discussed for several decades is the idea of locating the characteristics of situations or jobs within which behavior is highly influenced by personality. The current study utilized one method for identifying such characteristics. It is hoped that future research will be conducted to examine, and improve upon, the validity of the current framework.

\section{REFERENCES}

Ashton, M. C., \& Lee, K. (2007). Empirical, theoretical, and practical advantages of the HEXACO model of personality structure. Personality and Social Psychology Review, 11, 150-166

Dunning, D., Heath, C., \& Suls, J. (2004). Flawed selfassessment: Implications for health, education, and the workplace. Psychological Science in the Public Interest, 5, 69-106.

Hough, L. M., \& Ones, D. S. (2001). The structure, measurement, validity, and use of personality variables in industrial, work, and organizational psychology. In N. Anderson, D. S. Ones, H. K. Sinangil, \& C. Viswesvaran
(Eds.), Handbook of industrial, work, and organizational psychology: Vol. 1. Personnel psychology (pp. 233277). Thousand Oaks, CA: Sage.

Johnson, J. W., \& Carter, G. W. (2010). Validating synthetic validation: Comparing traditional and synthetic validity coefficients. Personnel Psychology, 63, 755-795.

Judge, T. A., \& Zapata, C. P. (2015). The person-situation debate revisited: Effect of situation strength and trait activation on the validity of the Big Five personality traits in predicting job performance. Academy of Management Journal, 58(4), 1149-1179.

Leary, M. R. (2005). The scientific study of personality. In V. Derlega, B. Winstead, \& W. Jones (Eds.) Personality: Contemporary theory and research (3rd ed.). Chicago: Nelson-Hall.

Lewin, K. (1935). A dynamic theory of personality. New York, NY: McGraw-Hill.

Meyer, R. D., Dalal, R. S., \& Hermida, R. (2010). A review and synthesis of situational strength in the organizational sciences. Journal of Management, 36, 121-140.

Nye, C. D., Su, R., Rounds, J., \& Drasgow, F. (2012). Vocational interests and performance a quantitative summary of over 60 years of research. Perspectives on Psychological Science, 7, 384-403.

Ones, D. S., Viswesvaran, C., \& Schmidt, F. L. (1993). Comprehensive meta-analysis of integrity test validities: Findings and implications for personnel selection and theories of job performance. Journal of Applied Psychology, 78, 679-703.

Peterson, N. G., Mumford, M. D., Borman, W. C., Jeanneret, P. R., \& Fleishman, E. A. (Eds.). (1999). An occupational information system for the 21 st century: The development of $O^{\star} N E T$. Washington, DC: American Psychological Association.

Peterson, N. G., Wise, L. L., Arabian, J., \& Hoffman, R. G. (2001). Synthetic validation and validity generalization: When empirical validation is not possible. In J. P. Campbell \& D. J. Knapp (Eds.), Exploring the Limits of Personnel Selection and Classification (pp. 411-451). Mahwah, NJ: Erlbaum.

Sackett, P. R., \& Walmsley, P. T. (2014). Which personality attributes are more important in the work place? Perspectives on Psychological Science, 9, 538-551.

Scherbaum, C. A. (2005). Synthetic validity: Past, present, and future. Personnel Psychology, 58, 481-515.

Schmidt, F. L., \& Hunter, J. E. (1998). The validity and utility of selection methods in personnel psychology: Practical and theoretical implications of 85 years of research findings. Psychological Bulletin, 124, 262-274.

Tett, R. P., \& Burnett, D. D. (2003). A personality trait-based interactionist model of job performance. Journal of Applied Psychology, 88(3), 500-517.

Tippins, N., \& Hilton, M. (Eds.). (2010). A database for a changing economy: Review of the Occupational Information Network $\left(O^{\star} N E T\right)$. Washington, DC: The National Academies Press.

RECEIVED 5/23/16 ACCEPTED 11/16/16 


\section{Jobs Included in the Analysis}

- Retail Salespersons

- Cashiers

- Combined Food Preparation and Serving Workers, In-

cluding Fast Food

- Office Clerks, General

- Registered Nurses

- Customer Service Representatives

- Waiters and Waitresses

- Laborers and Freight, Stock, and Material Movers, Hand

- Secretaries and Administrative Assistants, Except Legal,

Medical, and Executive

- Janitors and Cleaners, Except Maids and Housekeeping

Cleaners

- General and Operations Managers

- Stock Clerks and Order Fillers

- Heavy and Tractor-Trailer Truck Drivers

- Bookkeeping, Accounting, and Auditing Clerks

- Nursing Assistants

- First-Line Supervisors of Office and Administrative Support Workers

- Sales Representatives, Wholesale and Manufacturing,

Except Technical and Scientific Products

- Elementary School Teachers, Except Special Education

- Maintenance and Repair Workers, General

Personal Care Aides

- First-Line Supervisors of Retail Sales Workers

- Teacher Assistants

- Accountants and Auditors

- Team Assemblers

- Cooks, Restaurant

- Security Guards

- Receptionists and Information Clerks

- Secondary School Teachers, Except Special and Career/

Technical Education

- Business Operations Specialists, All Other

- Maids and Housekeeping Cleaners

- Landscaping and Groundskeeping Workers

- First-Line Supervisors of Food Preparation and Serving

Workers

- Construction Laborers

- Food Preparation Workers

- Sales Representatives, Services, All Other

- Home Health Aides

- Light Truck or Delivery Services Drivers

- Executive Secretaries and Executive Administrative

Assistants

- Licensed Practical and Licensed Vocational Nurses

- Packers and Packagers, Hand

- Software Developers, Applications

- Shipping, Receiving, and Traffic Clerks

- Police and Sheriff's Patrol Officers
- Automotive Service Technicians and Mechanics

- Middle School Teachers, Except Special and Career/

Technical Education

- Substitute Teachers

- Carpenters

- Lawyers

- First-Line Supervisors of Production and Operating

Workers

- Management Analysts

- Medical Assistants

- Childcare Workers

- Bartenders

- Electricians

- Computer User Support Specialists

- Computer Systems Analysts

- Industrial Truck and Tractor Operators

- Cooks, Fast Food

- Financial Managers

- Medical Secretaries

- Tellers

- Dishwashers

- Bus Drivers, School or Special Client

- First-Line Supervisors of Construction Trades and Extraction Workers

- Billing and Posting Clerks

- Inspectors, Testers, Sorters, Samplers, and Weighers

- Counter Attendants, Cafeteria, Food Concession, and

Coffee Shop

- Market Research Analysts and Marketing Specialists

- Human Resources Specialists

- Counter and Rental Clerks

- First-Line Supervisors of Mechanics, Installers, and

Repairers

- Correctional Officers and Jailers

- Helpers--Production Workers

- Dining Room and Cafeteria Attendants and Bartender

Helpers

- Driver/Sales Workers

- Cooks, Institution and Cafeteria

- Machinists

- Software Developers, Systems Software

- Packaging and Filling Machine Operators and Tenders

- Insurance Sales Agents

- Hosts and Hostesses, Restaurant, Lounge, and Coffee

Shop

- Plumbers, Pipefitters, and Steamfitters

- Welders, Cutters, Solderers, and Brazers

- Pharmacy Technicians

- Network and Computer Systems Administrators

- Managers, All Other

- Sales Managers 
- Social and Human Service Assistants

- Preschool Teachers, Except Special Education

- Bill and Account Collectors

- Operating Engineers and Other Construction Equipment Operators

- Hairdressers, Hairstylists, and Cosmetologists

- Sales Representatives, Wholesale and Manufacturing,

Technical and Scientific Products

- Computer and Information Systems Managers

- Cleaners of Vehicles and Equipment

- Recreation Workers

- Securities, Commodities, and Financial Services Sales

Agents

- Dental Assistants

- Industrial Machinery Mechanics

- Physicians and Surgeons, All Other

- Medical and Health Services Managers

- Firefighters

- Postal Service Mail Carriers

- Computer Programmers

- Loan Officers

- Production, Planning, and Expediting Clerks

- Pharmacists

- Purchasing Agents, Except Wholesale, Retail, and Farm

Products

- Child, Family, and School Social Workers

- Amusement and Recreation Attendants

- Paralegals and Legal Assistants

- Mechanical Engineers

- Teachers and Instructors, All Other, Except Substitute

Teachers

- Farmworkers and Laborers, Crop, Nursery, and Greenhouse

- Administrative Services Managers

- Claims Adjusters, Examiners, and Investigators

- Civil Engineers 